\title{
Oesophagealpapillomatosis in a Patient with History of Genital Warts
}

\author{
Sabbah Meriam ${ }^{1 *}$, Briki Ines ${ }^{1}$, Bellil Nawel ${ }^{1}$, Jouini Raja ${ }^{2}$ and Bibani Norsaf ${ }^{1}$ \\ ${ }^{1}$ Department of gastroenterology, Habib Thameur Hospital, Tunisia \\ 2Department of pathology, Habib Thameur Hospital, Tunisia
}

*Corresponding author: Sabbah Meriam, Department of gastroenterology, Habib Thameur Hospital, Tunisia, e-mail: sabbah_meriam@yahoo.fr

Received: 22 Aug, 2020 | Accepted: 07 Dec, 2020 | Published: 12 Dec, 2020

Citation: Meriam S, Ines B, Nawel B, Raja N, Norsaf B (2020) Oesophagealpapillomatosis in a Patient with History of Genital Warts. J Clin Case Stu 5(4): dx.doi.org/10.16966/2471-4925.209

Copyright: (C) 2020 Meriam S, et al. This is an open-access article distributed under the terms of the Creative Commons Attribution License, which permits unrestricted use, distribution, and reproduction in any medium, provided the original author and source are credited.

\section{Abstract}

Extensive forms of squamous esophagealpapilloma are rare. We report a case of 54-year-old papillomatousoesophageal lesion. Patient was negative for HPV infection. He was put on IPP therapy with plans of endoscopic follow up.

\section{Key clinical message}

This case illustrates the synergic action of chronic mucosal irritation and HPV infection in the development of this tumor. It also shows there should be further screening for other sites of HPV infection if genital warts or other location is noted.

\section{Introduction}

Extensive forms of squamous esophageal papilloma represent rare endoscopic finding and the management is only reported in few case reports of literature [1-3].We report a rare case of 54-year-old woman with a 6 year history of heartburn and recent onset of vomiting with digestive bleeding who presented a papillomatousoesophageal lesion confirmed histologically.

\section{Case report}

A 54-year-old woman presented to the Gastroenterology department for heartburn and two episodes of hematemeses. She reported a 6-year history of heartburn and esophageal dysphagia to solids. Her symptoms worsened recently with the onset of recurrent vomiting associated with epigastric pain. She denied any associated weight loss, changes in her bowel pattern, melena or history of indigestion. Although she showed no symptom of anemia and dizziness, laboratory investigations found a normocytic normochromic anemia with a hemoglobin level of $11 \mathrm{~g} / \mathrm{dl}$.

Upper endoscopy showed innumerable polypoid and fungating wart-like lesions involving more than $75 \%$ of the distal esophagus circumference as well as two longitudinal mucosal erosions greater than five $5 \mathrm{~mm}$ located between the latter lesions, a small hiatal hernia, as well as a nodular appearance of the duodenal mucosa (Figure 1).

Multiple biopsy specimens were taken from the esophageal lesions as well as a few from the duodenum mucosa and sent for pathological examination.
The biopsy specimens of the sampled esophageal lesions showed squamous papillomas characterized by finger-like projections of a fibrovascular core covered by mature squamous epithelium with no dysplastic cells detected (Figure 2).The duodenal specimens showed an unspecific duodenitis.

Upon further questioning, the patient reported genital warts that have been removed by her dermatologist years ago but the lesions have reemerged. She was also being regularly tested by a pap smear for cervical cancer; the last test is reportedly negative.

The biopsy samples were tested negative for HPV infection using in situ hybridization (ISH)/ p16 immunochemistry expression. We put the patient on proton pump inhibitor (PPI) therapy with plans for endoscopic follow-up.

\section{Discussion}

Esophageal squamous papilloma (ESP) is a rare benign epithelial tumor with a reported prevalence of $0,01 \%-0,45 \%$ [1].

Typically, these lesions present as a solitary sessile formation with warty-like surface, small in size and mostly in the distal esophagus[2]. Extensive lesions or esophageal papillomatosis (OP) are an even more rare endoscopic finding with only a few case reports described in the literature [3].

ESP can be confused endoscopically with glycogenic acanthosis, verrucouscarcinoma, squamous cell carcinoma. The diagnosis requires biopsies. Although generally asymptomatic, extensive lesions of ESP were associated with dysphagia and peptic disease symptoms such as our case study [1].

The underlying pathogenesis is still controversial but mainly two risk factors have been reported: HPV infection most commonly type 16 but the majority of ESP lesions tested negative $[2,4,5]$ and chronic mucosal irritation associated with reflux or oesophagitis as many cases have shown [6]. Hence, many reports suggest the synergic 


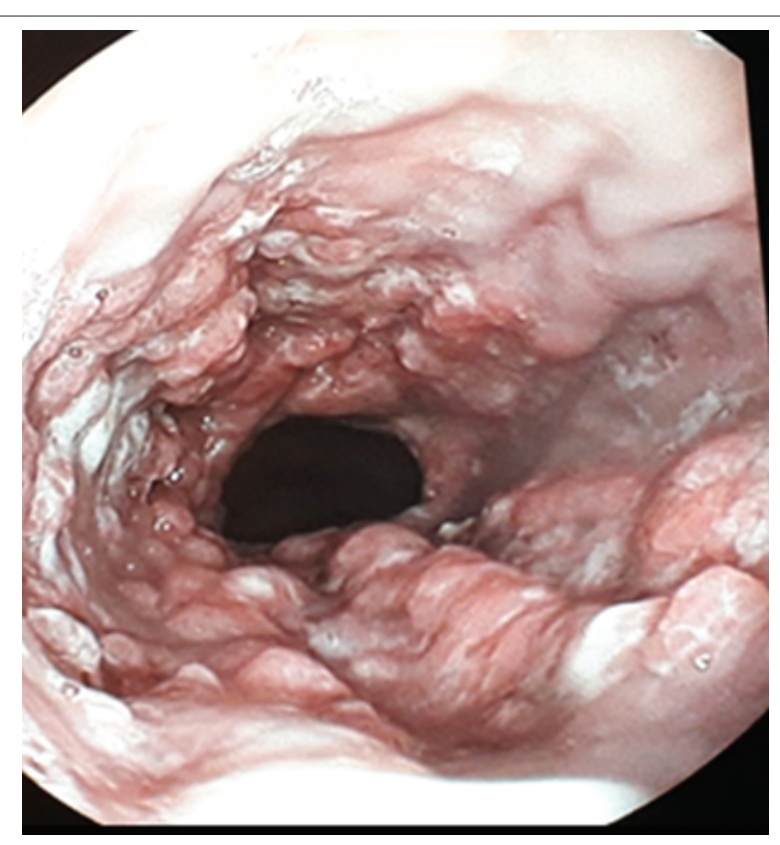

Figure 1: Upper endoscopy: innumerable polypoid and fungating wart-like lesions involving more than $75 \%$ of the distal esophagus circumference.

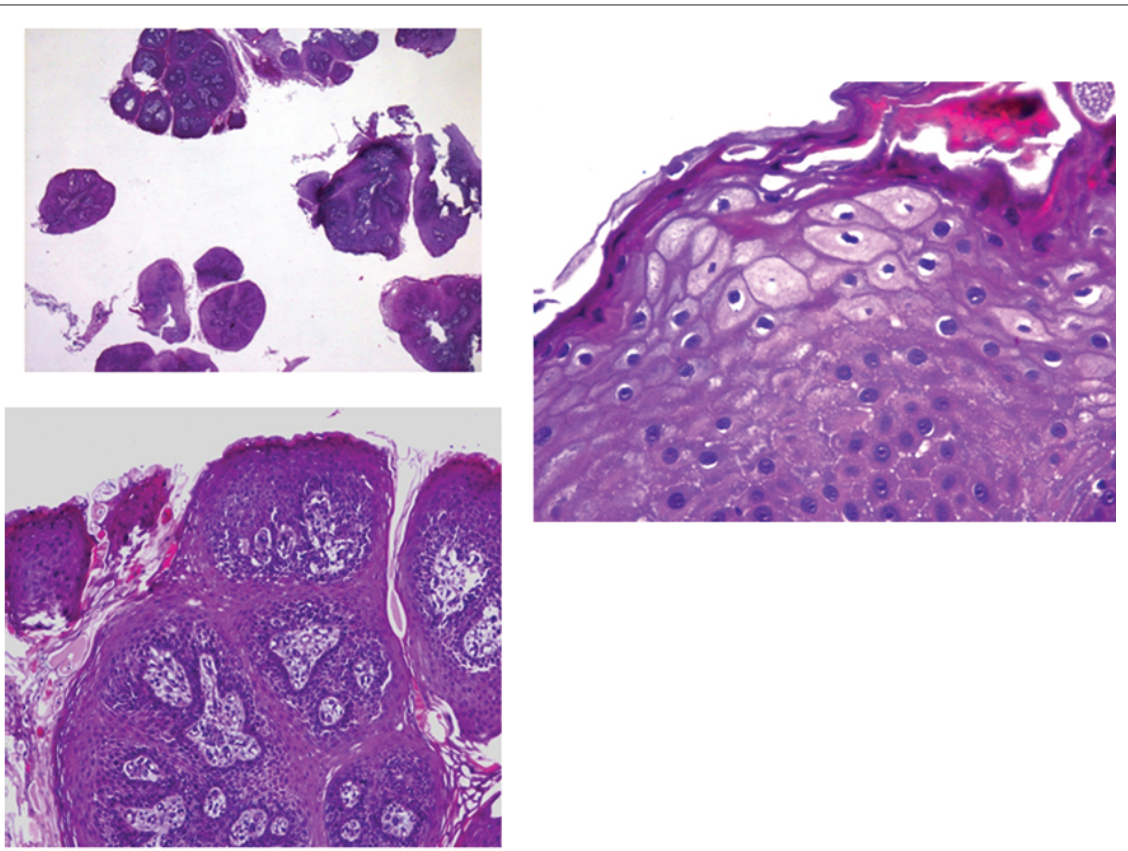

Figure 2: Oeophageal biopsy: squamous papillomas characterized by finger-like projections of a fibrovascular core covered by mature squamous epithelium with no dysplastic cells detected.

action might be necessary [2]. In our case, the patient has multiple distal papillomas with a hiatal hernia and mucosal breaks suggesting reflux oeophagitis and biopsy specimens tested for HPV infection were negative.

There is no association between ESP and esophageal cancer [3] although squamous papilloma is considered a premalignant lesion in other mucosal locations (oral, pharyngeal and anogenital. Malignant transformation has been reported however in a few case reports of OP
[7,8]. Among the risk factors for malignancy: esophageal stricture, dysphagia, and virulent HPV strains [9].

The management of ESP is not consensual yet in the literature Small solitary lesions have been successfully treated with endoscopic resection using biopsy forceps, snare polypectomy and cautery and recently radiofrequency ablation $[1,10]$. During follow up after endoscopy removal examination, one study found recurrenceis uncommon [1]. However, extensive esophageal papillomatosis is 
still a matter of research due to the paucity of reported cases: several treatment options were suggested mainly protons pumps inhibitors treatment [9], if failed, the endoscopic removal of the largest lesions often requiring endoscopic mucosal resection [11]. Surgical resection has even been advocated when malignancy is suspected [7] or for extensive papillomatosis [12] .If no specific treatment is undertaken, surveillance endoscopy should always be considered given the malignancy potential. However, no specific surveillance strategy has been defined. In our case, the patient is scheduled for endoscopic follow up.

Author's contribution: Sabbah Meriam, Briki Ines, and Bellil Nawel wrote the manuscript, Jouini Raja Gives the pathology pictures, Bibani Norsaf held the case and performed upper endoscopy.

\section{References}

1. Szántó I, Szentirmay Z, Banai J, Nagy P, Gonda G, et al. (2005) Squamous papilloma of the esophagus. Clinical and pathological observations based on 172 papillomas in 155 patients. Orv Hetil 146: 547-552.

2. Odze R, Antonioli $D$, Shocket $D$, Noble-Topham $S$, Goldman $H$, et al. (1993) Esophageal squamous papillomas. A clinicopathologic study of 38 lesions and analysis for human papillomavirus by the polymerase chain reaction. Am J Surg Pathol 17: 803-812.

3. Mosca S, Manes G, Monaco R, Bellomo PF, Bottino V, et al. (2001) Squamous papilloma of the esophagus: long-term follow up. $J$ Gastroenterol Hepatol 16: 857-861.
4. Poljak M, Orlowska J, Cerar A (1995) Human papillomavirus infection in esophageal squamous cell papillomas: a study of 29 lesions. Anticancer Res 15: 965-996.

5. Syrjänen KJ (2002) HPV infections and oesophageal cancer. J Clin Pathol 55: 721-728.

6. Carr NJ, Monihan JM, Sobin LH (1994) Squamous cell papilloma of the esophagus: a clinicopathologic and follow-up study of 25 cases. Am J Gastroenterol 89: 245-248.

7. Borgulya M, Lorenz D, Vieth M, Ell C, Pohl J (2011) Extensive Papillomatose des Ösophagus mit maligner Transformation des Plattenepithels. Z Gastroenterol 49: 1475-1478.

8. Attila T, Fu A, Gopinath N, Streutker CJ, Marcon NE (2009) Esophageal papillomatosis complicated by squamous cell carcinoma. Can J Gastroenterol 23: 415-419.

9. Gençdal G, Degirmencioglu S, Akyıldız M (2018) Diffuse Esophageal Squamous Papillomatosis Covering the Entire Esophagus. Clin Gastroenterol Hepatol 16: 28.

10. del Genio G, del Genio F, Schettino P, Limongelli P, Tolone S (2015) Esophageal papilloma: Flexible endoscopic ablation by radiofrequency. World J Gastrointest Endosc 7: 290-294.

11. Kim E, Byrne M, Donnellan F (2012) Endoscopic mucosal resection of esophageal squamous papillomatosis. Can J Gastroenterol 26: 780-782.

12. Tanimu S, Rafiullah, Resnick J, Onitilo AA (2014) Oesophageal papillomatosis, not amenable to endoscopic therapies, treated with oesophagectomy. Case Rep. 